\title{
SMART PROJECTS: MULTI-AGENT SOLUTION FOR AEROSPACE APPLICATIONS
}

\author{
P. SKOBELEV ${ }^{1}$, S. KOZHEVNIKOV ${ }^{2}$, I. MAYOROV ${ }^{2}$, D. POLUDOV ${ }^{2}$ \& E. SIMONOVA ${ }^{1,2}$ \\ ${ }^{1}$ Samara National Research University, Russia. \\ ${ }^{2}$ Smart Solutions, Ltd, Russia.
}

\begin{abstract}
Modern aerospace enterprises tend to utilize new advantages of networking organizations for increasing business efficiency. In practice, it requires introduction of a new type of project management stimulating the self-organization and active interaction between actors in order to make coordinated and effective decisions on resource allocation, both within the individual project teams and between the teams. In this paper, we propose the concept of new project management for networking organizations and describe the multi-agent system 'Smart Projects' for supporting decision-making to maximize productivity and efficiency of human resources. The system supports self-organization of teams with ongoing adaptive planning and communication with employees. This provides more coordinated, flexible and efficient resource utilization in case of unexpected events. The functionality and architecture of Smart Projects system are presented. The comparison with the traditional CIPLEX solution shows that quality of multi-agent scheduler could be worse up to $15 \%$ in batch mode but it is 10 times faster and can work in adaptation mode with smart manual re-work of schedules via negotiations with team members. First results of system application show that developed system can help to increase employees work efficiency - by 10-15\%, reduce efforts on tasks scheduling by 3-4 times, reduce the time of response to unexpected events by 2-3 times and increase of the percentage of enterprise projects completed within the budget and time by $15-30 \%$. The prospects for further developments are given. Keywords: multi-agent technology, project management, real time, resource planning and scheduling, self-organization
\end{abstract}

\section{INTRODUCTION}

The challenges of global economy associated with the growing complexity of business, priory uncertainty and high dynamics of supply and demand make businesses look for new approaches to increase the efficiency of the modern project-based enterprises [1-4].

Aerospace enterprises present one of the examples of extremely complex projects, which deal with best-in-class knowledge and talents of engineers and highly unique and innovative technical objects, systems and components. Traditional management in such projects is not working well because of high complexity objects and processes, dealing with uncertainty, interdependency of many factors, creativity and knowledge of engineers, etc. The solution of this problem requires a paradigm shift from centralized, monolithic, hierarchical top-down structures in project management to talent-driven and result-oriented networking organizations that are based on the new principles of self-organization of project teams and self-motivation of engineers [5].

However, most attempts to achieve this type of organizations and develop new software solutions for project management have failed because of the lack of self-organized systems to support project tasks scheduling with horizontal interactions and coordination between employees. A solution is required that can adaptively allocate human resources with the view on their interests, competencies and task load and provide event-driven capacity planning for teams as well as real-time scheduling and optimization of personal tasks in multi-project environments. 
One of the main features of such a new solution must be the possibility to communicate in real time and with employees on all levels for best possible execution of plans in time and in budget, with quality and minimum risks.

In this paper new solution 'Smart Projects' for project management will be introduced, which is utilizing multi-agent technology for real-time resource allocation, scheduling and optimization, as well as monitoring and control of results and communication with engineers.

In the first sections of this paper we will introduce the key requirements and a new approach for project and resource management for aerospace enterprises and discuss the main ideas of this new solution. The second section will be focused on functionality and architecture of the solution and the third section will consider the first results of development and use of the solution in Rocket \& Space Corporation 'Energia' (Russia).

Key results and perspectives will be summarized in the conclusion section.

\section{MODERN REQUIREMENTS FOR PROJECT MANAGEMENT IN AEROSPACE APPLICATIONS}

The complexity of project management in aerospace applications is fully recognized by toplevel industry managers. The progress of management in aerospace industry within the last decades is presented on Figure 1.

This diagram and Table 1 show the evolution of management style in aerospace enterprises from linear structures - to matrix and networks.

The modern agenda of innovative ideas on how to increase productivity and efficiency of project management in such organizations includes the following [6]:

1. Introduce principles of real-time economy and full transparency for profit sharing with employees;

2. Solve complex problems of project resource allocation, scheduling, optimization and control in communication with engineers with the view on their individual interests, competencies and experience;

3. Provide adaptive re-scheduling of tasks across all projects and teams in real time;

4. Stimulation \& encouragement of new ideas on all levels in the organization;

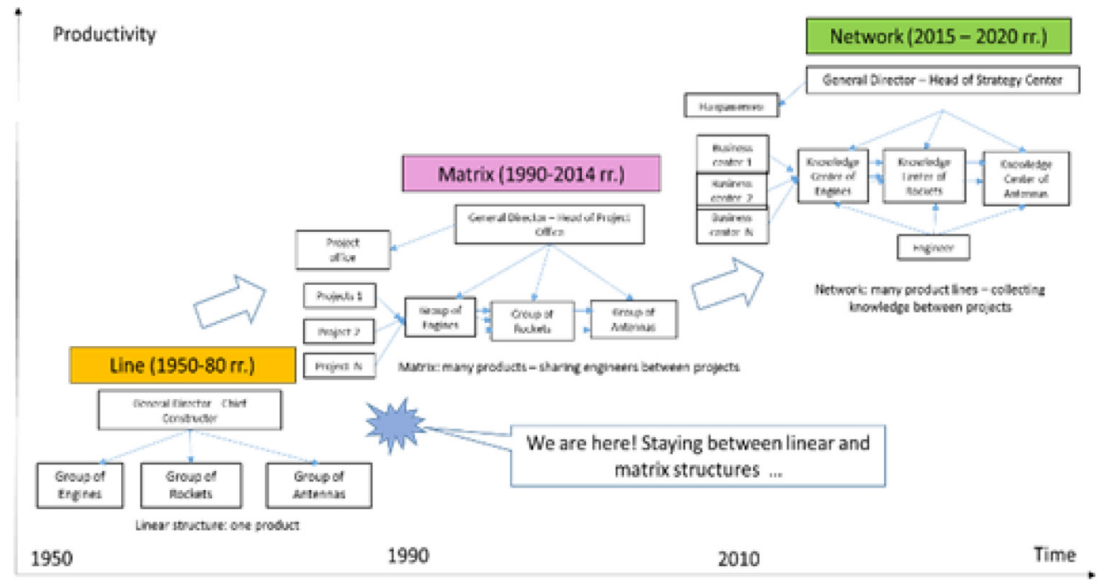

Figure 1: The progress of management in aerospace industry. 
Table 1: Traditional vs Networking enterprises.

\begin{tabular}{|c|c|}
\hline Traditional enterprise & Networking enterprise \\
\hline Centralization of functions & Decentralizing of functions \\
\hline $\begin{array}{l}\text { Hierarchical structure, rigid relations } \\
\text { between employees }\end{array}$ & $\begin{array}{l}\text { Networking structure, flexible relations } \\
\text { between employees }\end{array}$ \\
\hline Closed to environment & Open to environment \\
\hline $\begin{array}{l}\text { The knowledge in decision-making is rigidly } \\
\text { fixed, the decisions are made according to } \\
\text { formal rules of business processes }\end{array}$ & $\begin{array}{l}\text { The knowledge is not fixed, priority is in } \\
\text { generating new knowledge, the decisions are } \\
\text { made not formally and are situation-driven }\end{array}$ \\
\hline $\begin{array}{l}\text { Planning approach, all resources are } \\
\text { allocated in advance }\end{array}$ & $\begin{array}{l}\text { Market approach, the resources are allocated } \\
\text { when necessary }\end{array}$ \\
\hline $\begin{array}{l}\text { Top-down communication according to the } \\
\text { hierarchy }\end{array}$ & $\begin{array}{l}\text { Peer-to-peer communication as required for } \\
\text { problem-solving }\end{array}$ \\
\hline $\begin{array}{l}\text { Batch planning, following the regulations } \\
\text { and instructions }\end{array}$ & $\begin{array}{l}\text { Flexible planning in real time, following } \\
\text { events }\end{array}$ \\
\hline Total control & Self-motivation \\
\hline Fixed salary & Dynamic salary \\
\hline
\end{tabular}

5. Reduction or removal of bureaucratic barriers for collaboration between employees in different departments;

6. Recognition of the role of knowledge in project management;

7. Acknowledgement of learning through trial and error and failures;

8. Result-oriented teamwork;

9. Development of reward systems that promotes the best results, etc.

However, in practice these innovative ideas demand the break of the existing stereotypes in project management and results in developing new approaches with a fundamental change of mind-sets of employees.

The main problem is how to help regular engineers to grow and become open-minded forward-thinking innovators.

One of the approaches could be to provide more freedom in decision-making and catalyze efficient project management motivating young leaders to achieve outstanding results sharing project profits and risks with the enterprise.

\section{NEW APPROACH TO PROJECT MANAGEMENT FOR AEROSPACE ENTERPRISES}

The developed approach to new project management is introducing the new type of networking enterprise which will be organized as a more horizontal rather than vertical structure.

This networking enterprise will operate on the base of internal virtual market with 'uberization' of project tasks for employees, thus giving the engineers an opportunity to compete and cooperate in selecting and choosing tasks.

The key elements of such enterprise structure are business centers (BC) that work as virtual sub-companies operating in the internal market of the parent company (PC). Another key element are knowledge centers (KC) that act as resource pools for projects and become a 'home' for professional community of employees, where the level of qualification of 


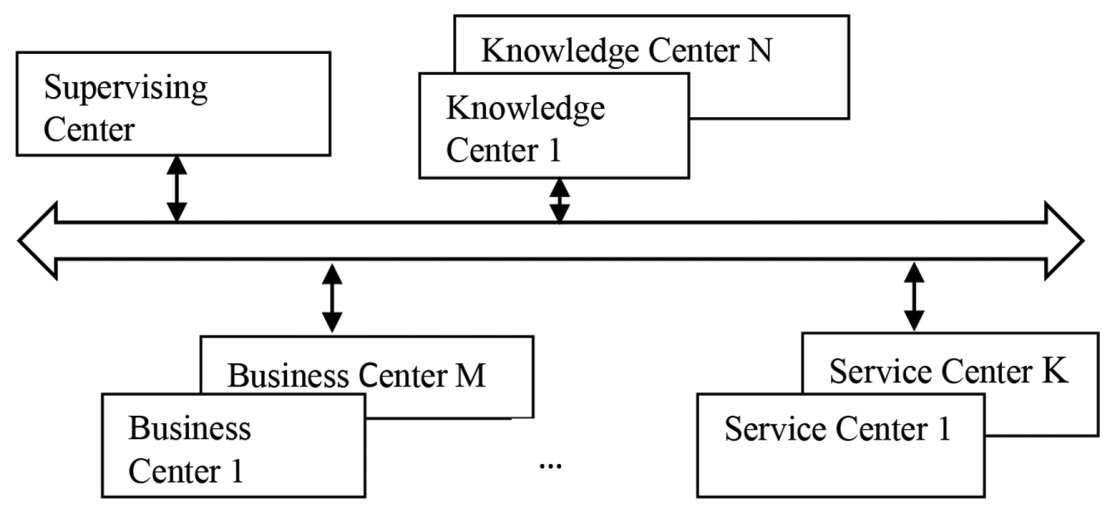

Figure 2: Step from hierarchy - to network of enterprise.

employees is determined, competence profiles are specified, market rates are estimated and individual trajectory of engineers competencies development is supported. Another element is service centers (SC) which provide special services for $\mathrm{BC}$ and $\mathrm{KC}$ and the supervising center (SVC), which is aimed at strategy development, monitoring of results and analytics. All the elements have their own profit \& losses reports.

Such approach helps to start transformation of traditional centralized, hierarchical and monolithic structure of real enterprise into a new structure which is more transparent, flexible and efficient for project management (Fig. 2).

Networking structure could be introduced as a virtual structure which runs in parallel with the existing one but needs to be fully supported by smart system for decision-making support in project management.

In such an organization each employee has the opportunity to offer his or her service to any $\mathrm{BC}, \mathrm{KM}$ or SC negotiating on the jobs and work hours for each project or service - in such case the payments for employees become variable and can grow in an unconstrained way. Employee's 'home' is also interested in this since it receives the interest for each employee that participates in $\mathrm{BC}$ projects.

For the long-term motivation of employees to reach outstanding results, we have designed the mechanism of virtual project shares (VPS) for the employees that reflect the personal input into each project and results achieved.

VPS are issued by owners and leaders of $\mathrm{BC}$ and $\mathrm{KC}$ with the view on results and employees can receive specific bonuses on this basis and also dividends of knowledge - if results are used in next projects.

As a result, all employees can compete and cooperate with each other for the success of projects, thus increasing the efficiency of the enterprise as a whole.

\section{MULTI-AGENT TECHNOLOGY FOR MANAGING RESOURCES}

The proposed solution is designed to support the full cycle of project resources management for networking enterprises, covering resource allocation, scheduling and optimization, communication with employees and monitoring the execution of tasks and quality of results in real time.

For this purpose, 'Smart Projects' solution is developed based on the concept of resource-and-demand networks (RDN) and multi-agent technology for real-time resource scheduling [7]. 
The multi-agent technology supports real-time decision-making in project management by allowing adaptive rescheduling of resources when new tasks and unexpected events occur. These disruptive events come both from out-side the organization and as a result of interaction amongst the team members. In this technology, each event triggers propagation of changes in plans which lead to the new schedule by shifting, reallocating or swapping the tasks of employees. Hereby a new project, new tasks, delays, changes in deadlines, execution progress updates, etc. can quickly be incorporated in the schedule.

The principles of multi-agent scheduling can be briefly described as follows:

1. Each order, project, project task, engineer or product has its own software agent;

2. All agents can receive messages with events, take decisions and communicate with other agents or users;

3. During decision-making agents use their own criteria, preferences and constraints;

4. The scheduling process is considered as a process of negotiations for finding consensus between agents;

5. For example, the task agent begins the scheduling by searching for the required resources;

6. If the appropriate employees are busy, a conflict is detected and negotiations are initiated;

7. During the negotiations different options are possible: the new task will be moved to a less appropriate resource, the previously occupying task will leave the required employees schedule or be shifted or tasks may be divided in parts, make swaps, etc.;

8. Even after having solved the initial conflicts and establishing a schedule, agents pro-actively continue to search for new options for better scheduling.

Multi-agent technology distinguishes the proposed solution from the existing mathematical solvers, in which all tasks and resources are considered as known in advance and, by principle, do not change adaptively during execution $[8,9]$.

The key classes of agents that act on behalf of the orders, projects, tasks, departments, employees and results are described in [10].

The schedule is considered 'optimal' and computations stops after achieving one of the three conditions: either when no agent can improve the solution anymore or the solution is oscillating near the achieved 'optimum' (balance of interests) or when the time for finding alternative solutions has elapsed.

\section{SMART PROJECTS: SOLUTION ARCHITECTURE}

The solution is designed with three-tier architecture containing a user interface, the multi-agent scheduling engine and a relational database (Fig. 3).

Each tier can be located at a separate server if needed.

The basic frameworks include the following:

1. Devexpress eExpress Application Framework (XAF) - supports Web-UI, Reports and system infrastructure;

2. Rich modern UI components based on ExtJS framework for interactive Gant and Pert chart and Kanban board;

3. MS Entity Framework - components for accessing and processing data from various databases (MS SQL Server, Oracle Database, Postgress, etc.) in .Net environment;

4. Tallend ESB - integration modules, etc. 


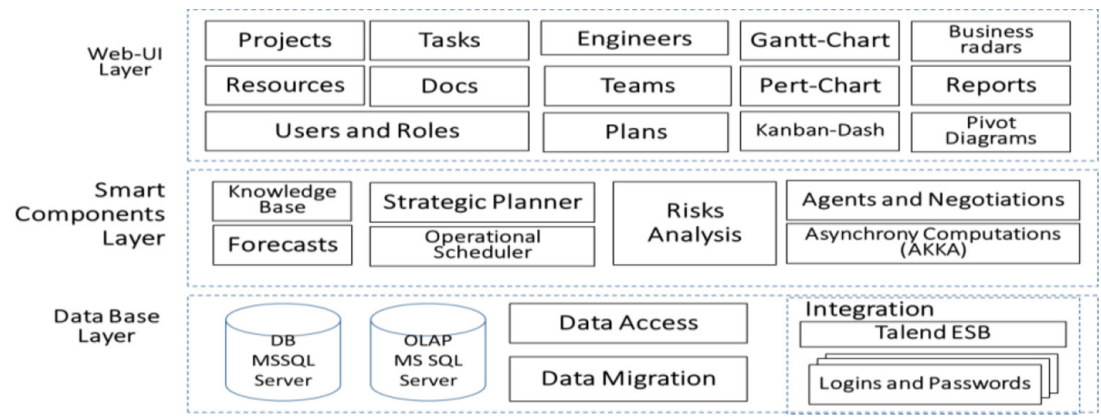

Figure 3: Solution architecture.

The key component of the solution is the application server with multi-agent engine that executes the adaptive scheduling based on events, interacts with subsystems, performs data processing and provides mechanisms for managing access rights in the system.

At the moment, there are two user interfaces:

1. The management interface is designed for tasks allocation, jobs scheduling, results monitoring, schedules modification and other similar functions.

2. The project team member interface allows the employee to select tasks, create new ones if required, specify their preferences and browse the list of preferred tasks, and also report the progress on work done.

The main components of the multi-agent scheduling engine are: dispatcher agent, message interaction service, agents lifecycle support service, services for creation and deletion of agents, support of the agent communication protocol and access to data scene [10].

An integration subsystem allows the system to interact with other information systems and currently Windchill and Microsoft Project are supported.

At runtime different events are imported which are processed by the scheduling subsystem in real time [10].

\section{USER INTERFACE OF SMART PROJECTS SOLUTION}

User interface represents the main functionality of the system. On the first screen the user can see the information about current projects, status of the project stages and tasks, KPIs and budget (Fig. 4).

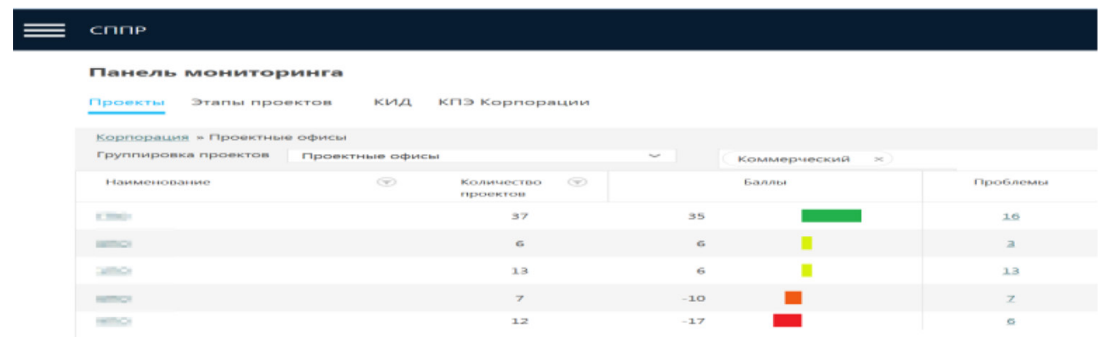

Figure 4: Home screen of smart projects. 
The system's main menu provides access to the following:

- projects - project details and schedule;

- tasks - current tasks execution status and results;

- employees - employees profiles and workload, virtual project shares;

- dynamics - workload reports and dashboards;

- knowledge base - ontology and scene representing the situation at the enterprise;

- services - additional services (MS Project integration, etc.).

The head of project team has the possibility to assign tasks manually or see results of tasks self-organization (Fig. 5).

On this screen, information is displayed using grid views with additional color indication of tasks status (not allocated, scheduled, in-progress, delayed, etc.).

The visual data grid component provides functionality for grouping, filtering and sorting data by any number of fields simultaneously. For example, the user can filter data by project, time range and responsible person.

The graphical representation of the project schedule over the whole resource set is done using the combined Gantt-Perth chart (Fig. 6), reflecting the dependencies between the tasks. Besides, the top chart on the screen displays the total department workload resources lack or excess.

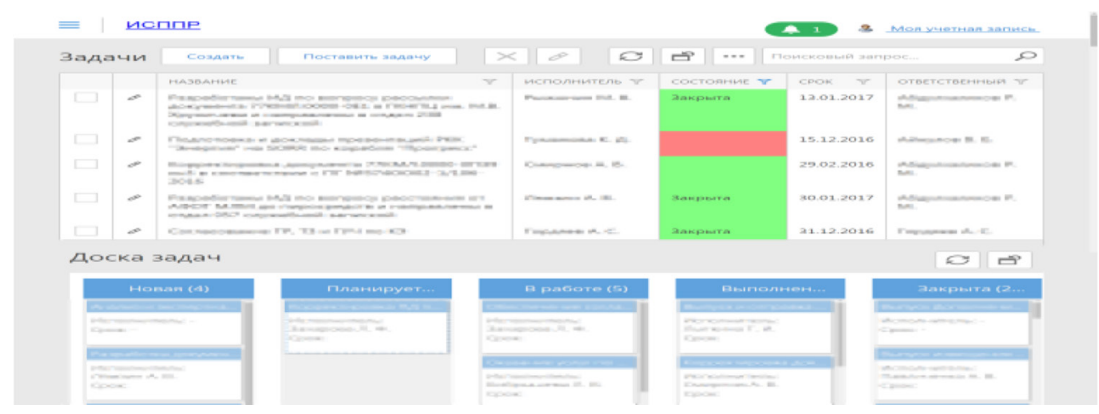

Figure 5: Current task log.

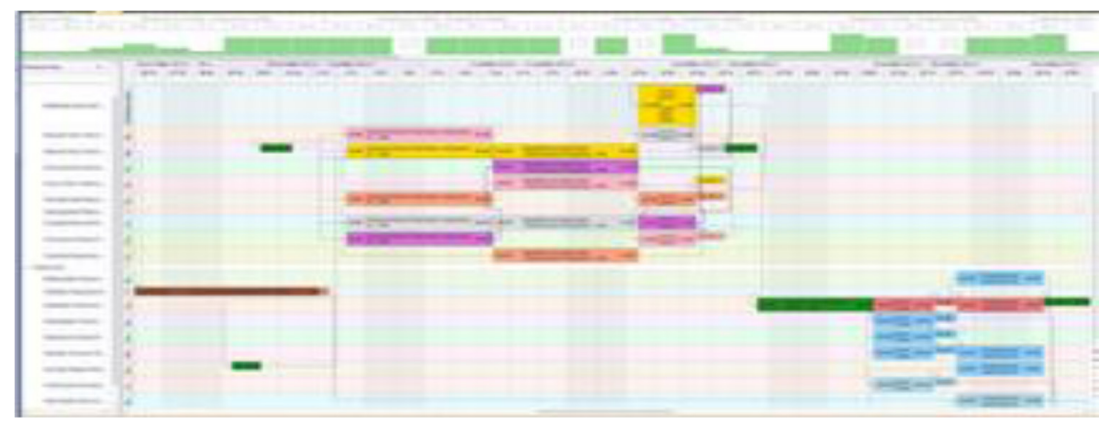

Figure 6: The schedule represented by Gantt chart. 


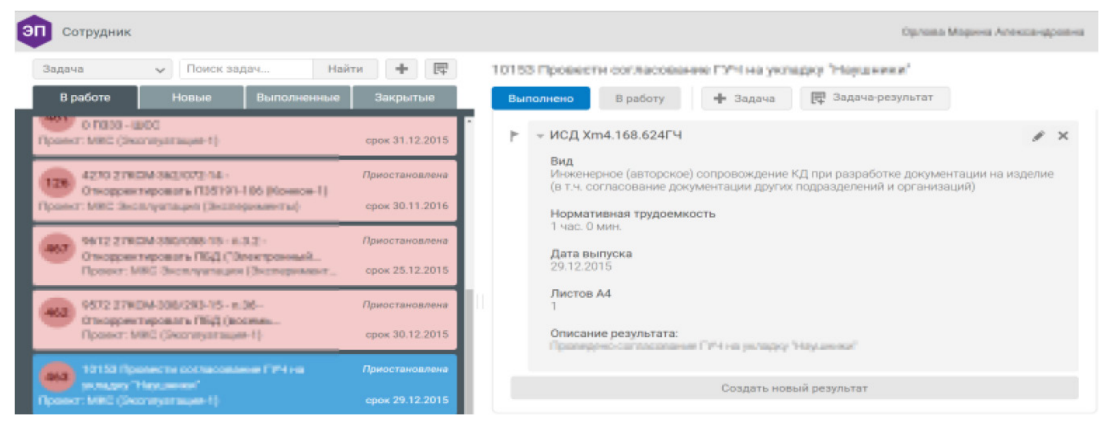

Figure 7: Project team member user interface.

The most interesting component is the 'project-member' user interface, which supports communication with users:

- browsing the suggested tasks and selecting the task to execute;

- task decomposition or creation of a new task, changing task parameters (for example, work estimation);

- accepting the task, starting the execution, specifying execution problems, task completion, requesting help for the task;

- ability to specify the attitude of the executor to the task, how much does he or she like it (the task, which executor doesn't like, can be reallocated);

- setting the preferences and constraints of the executor;

- event input (estimation of the work left, etc.);

- displaying tasks by statuses (not started, in progress, completed, etc.);

- task filtering using semantic descriptors etc.

A sample screenshot of the project-member user interface is shown in Figure 7.

This interface enables the system to interactively communicate with the users to obtain detailed information about their evaluation of the tasks and use this information to develop alternative schedules to achieve the best result as effectively as possible.

The tasks are not imposed on the user, but rather suggested, so the user can decide by accepting or declining. The application hereby uses statistics of the similar tasks executed before, but imports this knowledge letting the user revise the assumptions and if needed suggest new tasks, re-specify parameters, etc.

To monitor the results of the team a set of reports were developed to display general summaries of results for respective projects and departments. Dashboards are shown and updated in real time to display the dynamics of changes in the projects, for example, important tasks, new project stages, increase of the project workload, etc. (Fig. 8).

\section{MODELING THE TASK FLOW: QUALITY AND EFFICIENCY OF MAS}

To assess the quality and efficiency of the developed multi-agent system (MAS), Job Shop Scheduling test case was used for benchmarking, which was solved in the IBM ILOG CPLEX Optimization Studio 12 package for the criterion of minimizing Max span. For each set of test tasks, traditional combinatorial solutions were found using CPLEX. For the same sets, solutions were computed in the MAS, which were compared with the CPLEX solutions. 


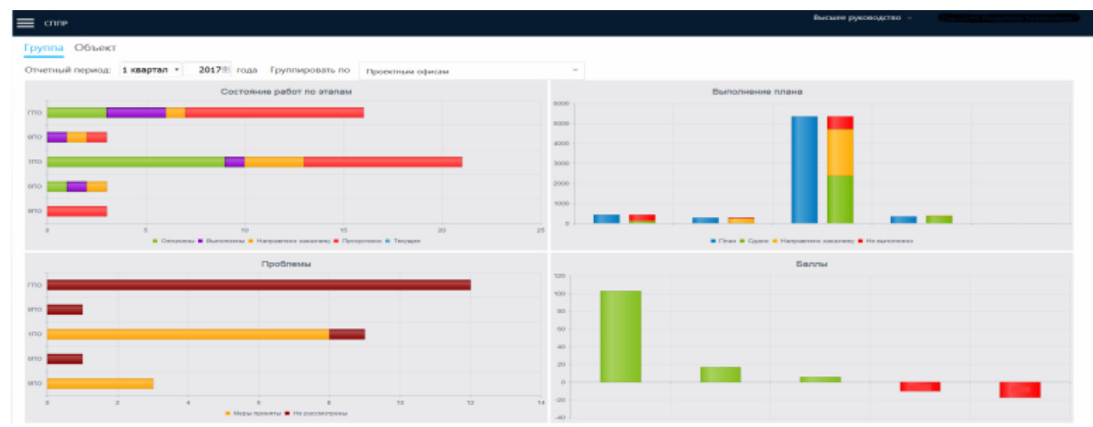

Figure 8: Reports and dashboards screens.

In our experiments, five resources were used for processing a task flows; each of which consists of five separate tasks that require execution on the specified resource. In total, there are 500 different tasks. The MAS plans them on the resources by the criterion of minimizing the Max span. The execution time of tasks varies from 1 to 5 conventional units of work and arrival times are exponentially distributed over an interval of 100 units of model time. The cost of tasks is proportional to their volume.

The ratio of maximum duration received by CPLEX to the duration received by the MAS was taken for comparing results (identified as a Quality of solution below). The total computation times in MAS and CPLEX were also measured. The experiments were carried out in Windows 10 on a typical workstation, which has a 4-core processor with a 2-GHz frequency and $4 \mathrm{~GB}$ of RAM. The results are shown in Figures 9 and 10.

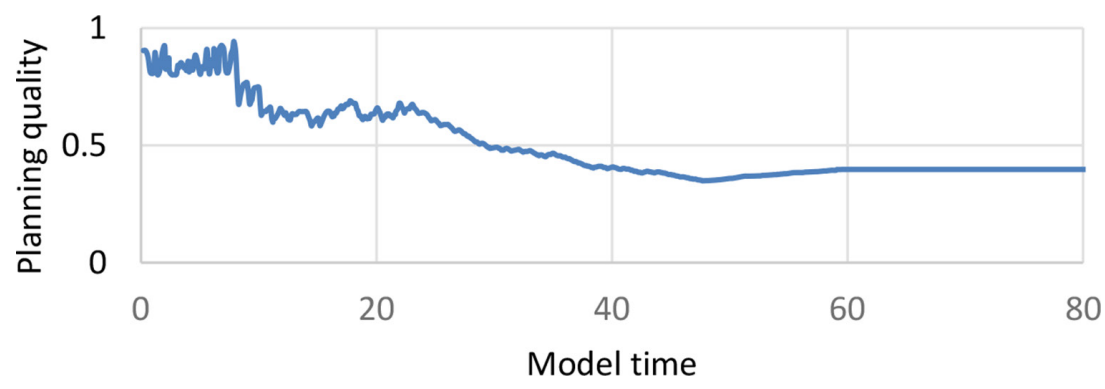

Figure 9: Quality of planning, depending on the model time.

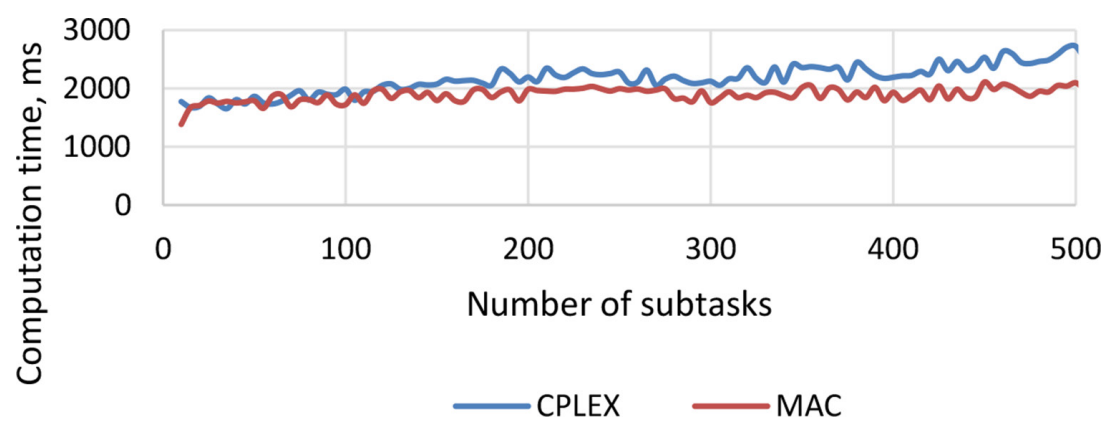

Figure 10: Computation time depending on the number of subtasks. 


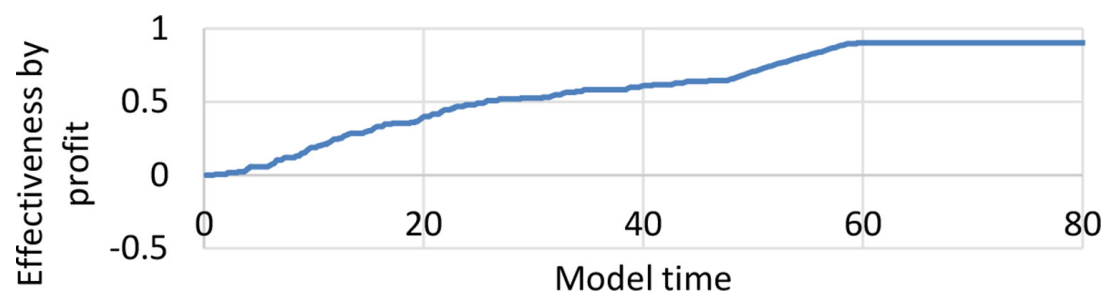

Figure 11: Planning efficiency depending on the model time.

At the beginning of modeling, the MAS result was about $85-90 \%$ (more on delay) of the CPLEX solution. Later, the quality was about $40 \%$. This is because in the beginning the resource system is relatively free, and the multi-agent scheduling yields results similar to the traditional algorithm. With further increase of the task flow, the multi-agent solution worsens its performance indicators.

However, according to the computational time, the multi-agent system is $20 \%$ ahead of CPLEX due to partial rescheduling, instead of a full search for the solution again (see Figure 10).

Efficiency of profit planning in the multi-agent system was also determined. Atomic tasks without links have been analyzed. Effectiveness of planning is evaluated by the profit brought by the planned tasks with a smaller deviation from the deadline. Since the multi-agent system planned more profitable tasks on a first-priority basis, the planning efficiency was $90 \%$, and the less profitable tasks were planned with delay (see Figure 11).

\section{THE IMPACT OF INTERCONNECTION OF TASKS ON THE QUALITY AND TIME OF PLANNING}

To compare the traditional planning of CPLEX package and the multi-agent system, an example of four tasks was taken, each of the tasks consisting of three operations that must be performed on three different resources that do not allow simultaneous execution of tasks. The tasks have the same priority level, appear at the same time, but their operations have different duration and order of execution on the resources (Table 2).

The objective function is to minimize total execution time.

As a result of planning by MAS and CPLEX, the following schedules were obtained (Figs. 12 and 13).

The quality of the schedule can be evaluated by the ratio of the maximum duration of all tasks using CPLEX and MAS, in this case 20/23 $=0.86$.

A more extensive experiment for comparing results of MAS and CPLEX planning was performed on 300 JSSP tasks, depending on their number; each of the operations has a

Table 2: Parameters of task operations and their sequence.

\begin{tabular}{lll}
\hline Task & Sequence of operation resources & Duration of operations \\
\hline 1 & $3,2,1$ & $3,2,9$ \\
2 & $3,1,2$ & $5,3,5$ \\
3 & $3,2,1$ & $1,7,1$ \\
4 & $1,3,2$ & $5,3,3$ \\
\hline
\end{tabular}




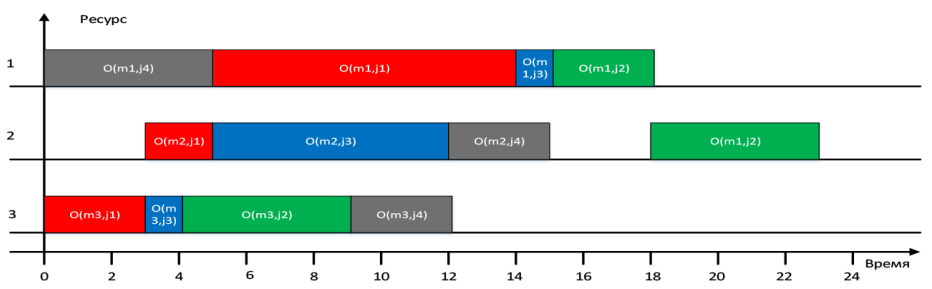

Figure 12: The schedule obtained by MAS for the example of four tasks.

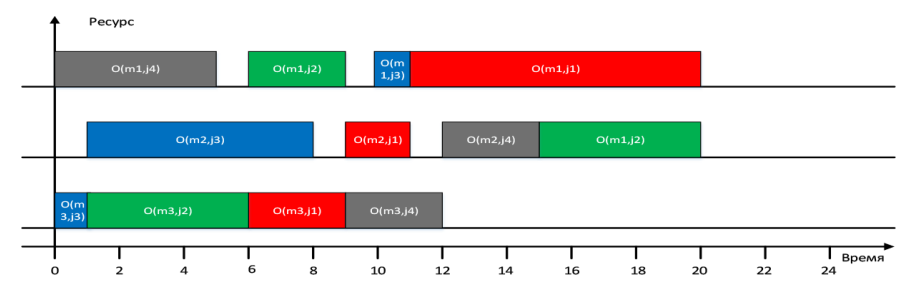

Figure 13: The schedule obtained by CPLEX (optimal result) for the example of four tasks.
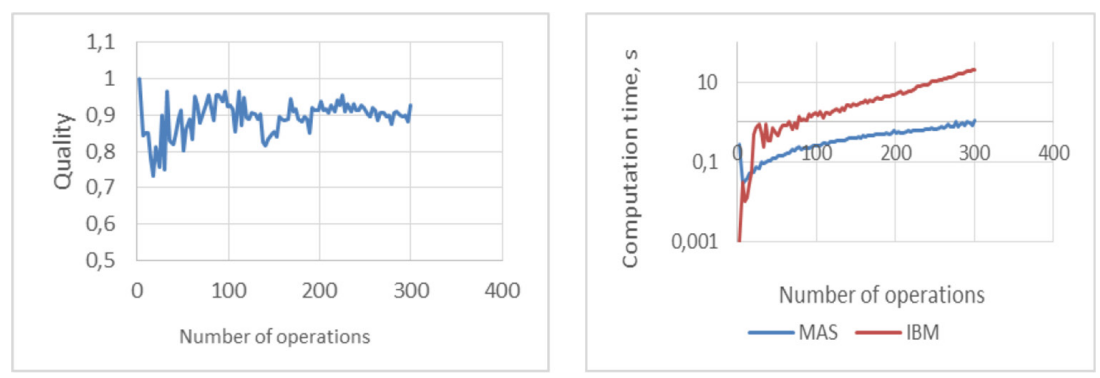

Figure 14: The criterion value and the computation time, depending on the number of planned operations.

duration of up to 10 units. The quality of the solution was determined by the ratio of the exact and MAS-solutions, the maximum execution time of all tasks.

The computation time was also measured (Fig. 14).

Analysis of the experiment shows that the MAS result is about $10-15 \%$ worse than the exact solution; however it is 10-20 times faster than CPLEX, which makes it possible to use MAS in areas where fast response to events is required.

\section{OBTAINED RESULTS AND PROSPECTS}

The first delivery of solution is made for the aerospace corporation 'Energia' and it shows a potential of the approach by increasing the efficiency of enterprise projects and support of the solution by both management and employees.

The first results include the following estimates:

- increase of the employees work efficiency - by 10-15\%;

- reduction of the efforts on tasks allocation, scheduling, and monitoring for running project - by 3-4 times; 
- increase of reusability of the existing resources (documents, components, etc.) - from $50 \%$ and more;

- reduction of the time of response to unexpected events - by 2-3 times;

- increase of the percentage of enterprise projects completed within the required budget and timeframe - by $15-30 \%$;

- platform for increasing the number of projects without increasing the number of managers.

The main prospects of further system development are associated with implementation of a knowledge base and network-centric p2p platform for coordination of work of different departments.

\section{CONCLUSIONS}

A new concept and approach of project management for aerospace enterprises is presented, which now is being tested at the aerospace corporation 'Energia'.

Practical application of the developed concept results in the shifting management paradigm from centralized decision-making and hierarchical structures towards networking organizations.

The software solution 'Smart Projects' was developed to support the proposed approach based on multi-agent technology. The comparison with the traditional CIPLEX solution in batch mode shows that quality of multi-agent solution could be worse about $15 \%$, but it is much faster and can work in adaptation mode.

The developed approach provides the opportunity for project team leaders and members to share profit with the enterprise in case of success - to motivate new generation of talents to achieving outstanding results.

The designed solution can be extended and applied to any other types of enterprises in the future.

\section{ACKNOWLEDGMENTS}

This paper was prepared with the financial support of the Ministry of Education and Science of the Russian Federation - contract №14.578.21.0137, project unique ID is RFMEFI57815X013.

\section{REFERENCES}

[1] Johnson, R., Kast, F. \& Rosenzweig, J., The theory and management of systems, McGraw-Hill Book Company: New York, 1967.

[2] Shepard, H., Changing relationships in organizations, Handbook of Organizations, eds., III, Rand McNally and Company: Chicago, 1965.

[3] Koestler, A., The ghost in the machine, Arcana books: London, 1989.

[4] Best Project Portfolio Management (PPM) Software, 2017, available at: https://www. g2crowd.com/categories/project-portfolio-management-ppm. (accessed March 30, 2017).

[5] Vittikh, V. Introduction to the theory of intersubjective management, SSC RAS: Samara, 2013.

[6] 'Open Innovations', Proceedings of the Moscow Forum of Innovations; Moscow, 2012.

[7] Rzevski, G. \& Skobelev, P., Managing complexity, WIT Press: London-Boston, 1st edition, 2014.

[8] Leung, J., Handbook of scheduling: algorithms, models and performance analysis, CRC Computer and Information Science Series, eds., Chapman \& Hall: London, 2004. 
[9] Skobelev, P., Multi-agent systems for real time adaptive resource management, Industrial agents: emerging applications of software agents in industry, eds., Elsevier, pp. 207-230, 2015.

[10] Kozhevnikov, S., Larukhin, V., Skobelev P., eds., Smart enterprise: Multi-agent solution for holonic enterprise resource management. Proceedings of the 12th IEEE/ACIS International Conference on Computer and Information Science, Niigata, Japan, pp. 111-116, 2013. 